\title{
Breve descrição sobre os kaiowá e guarani na graduação e pós-graduação
}

Celuniel Aquino Valiente ${ }^{1}$

DOI: http://dx.doi.org/10.20435/tellus.v18i36.502

\section{INTRODUÇÃO}

Sou Kaiowá, pertenço à parentela Aquino e Valiente da reserva indígena de Amambai, MS; o Aquino é parentela da minha mãe, e o Valiente parentela do meu pai. Toda parentela da minha mãe se autodeclara como kaiowá, e toda parentela do meu pai, como Guarani, mas desde o casamento dos meus pais e até no atual momento as duas parentelas formam um único coletivo ou uma única parentela, mesmo o meu pai sendo da parentela guarani, o meu fogo famíliar - che ypyky kuera se autoidentifica como pertencente ao coletivo kaiowá.

A reserva indígena de Amambaí é localizada no município de Amambaí, MS, com a dimensão de 2.400 ha, com a população de mais de 10 mil pessoas, composta por diversas parentelas. Existem quatro regiões na reserva: a região mais conhecida de fora é denominada de posto, onde se localiza a escola central, posto de saúde central e barracão comunitário, as sua periferias são ivernasa, sertãozinho, hugua e a região onde passa o rio Ppandui.

A reserva de Amambaí foi criada e demarcada entre 1915 e 1928, uma de oito reservas que o estado criou para acomodar algumas minorias parentelas e confinar a maioria restante em um espaço limitado e diminuto, de modo a deixar livre as terras para a ocupação agropastoril. Os tekoha - aldeias tradicionais dos kaiowá e guarani - localizavam-se esparramados na vasta região do sul de Mato Grosso do Sul, antes da chegada dos colonos estrangeiros. Ao chegar os colonos estrangeiros, várias comunidades tradicionais foram removidas violentamente do seu próprio território tradicional. E não preciso dos documentos para citar, existem vários lideres tradicionais que relatam essa experiência de remoção de sua comunidade tradicional.

\footnotetext{
${ }^{1}$ Universidade Federal da Grande Dourados, Dourados, Mato Grosso do Sul, Brasil.
} 
A minha trajetória na educação começou quando entrei no pré-escolar, na Missão Caiuá da minha reserva, quando tinha seis anos de idade; nessa escola, toda professora era não kaiowá e guarani, por isso relembro de muitos preconceitos que passei durante os meus anos iniciais nessa instituição escolar e, sobretudo, a ignorância por parte dessas professoras sobre as realidades e concepções, práticas e conhecimentos das crianças kaiowá e guarani. Pude perceber os preconceitos também com outras várias crianças de diversas parentelas e, desde então, fiquei traumatizado, não consigo fazer muita relação e diálogo com não índio; sou muito afetado pelo trauma desse meu passado, é como uma cicatriz que nunca vai sumir da minha vida.

Como naquela época (2001) a reserva já era populosa, a única renda que a maioria da família possui vem dos trabalhos escravos nas usinas de álcool e nas fazendas que se localizam nas redondezas da reserva, exceto alguma parentela que se acomodou trabalhando na educação e saúde com seu salário por mês, como também o cargo de capitania. Os recursos naturais, como nascente e floresta, quase não tinha na reserva, muitas famílias sofreram e sofrem até o dia de hoje esse espaço de confinamento.

A maioria da família tinha a esperança de que, pelo viés da escola, os seus filhos futuramente melhorariam a sua vida na reserva; no entanto as maiorias colocam os seus filhos nas escolas da aldeia ou da missão, porém, existem outras famílias que não possuem esperança na escola. Lembro-me a fala de um homem ou líder de uma família que criticava o pressuposto e o pensamento que a escola apresenta, ou melhor, os preconceitos que a escola apresenta sobre a diversidade de cada parentela.

No ensino básico, sexto, sétimo, oitavo, nono, e no ensino médio eu conclui na escola considerada indígena que fica na reserva, Escola Municipal Pólo Indígena Mbo'eroy Guarani e Kaiowá e Escola Estadual Indígena Mb'eroy Guarani e Kaiowá.

Em 2012, ingressei no curso de Ciências Sociais, na UEMS de Amambai, e conclui em 2016 com a monografia intitulada de Transformações e conflitos em torno das identificações forjadas pelos Guarani e Kaiowá da Reserva de Amambaí (2016), uma pesquisa realizada sobre a configuração política da reserva onde resido. 


\section{OS KAIOWÁ E GUARANI NAS GRADUAÇÕES}

Existem vários trabalhos já realizados sobre os indígenas pelos não indígenas e pelos próprios indígenas no Brasil. Da mesma forma, sobre os coletivos Kaiowá e Guarani de Mato Grosso do Sul, a partir da metade do século passado (XX) e até os dias atuais (2017), as existentes produções etnográficas são diversas e imensas nas várias esferas de sua vida social, ecológica, cosmológica e sociopolítica.

Com essas pesquisas etnográficas recentes de vários antropólogos ou etnólogos não indígenas, o olhar sobre esses coletivos, sobretudo do Kaiowá, vem sendo diferenciado no sentido de uma concepção e olhar mais treinado com essa pesquisa e teoria já produzida sobre o seu sistema social e cosmologia. No entanto a etnologia chegou ao seu auge com a crítica e rompimento desses pensamentos modernos europeus que subalternizam vários coletivos humanos como Kaiowá e Guarani.

Mas essas contribuições na esfera da etnologia indígena sempre foram dos pesquisadores não indígenas. Nesse sentido, os coletivos indígenas são sempre objetos de pesquisa dos pesquisadores homens e mulheres de fora, ou seja, dos brancos e das brancas. Mas, nos últimos anos, tem acontecido o que até então nunca tinha acontecido, ou seja, vem crescendo o número de jovens de vários coletivos indígenas em diferentes graduações e pós-graduações nas universidades, tanto na universidade pública quanto na universidade privada no Brasil. Por exemplo, como eu próprio, graduado em Ciências Sociais na Universidade Estadual de Mato Grosso do Sul (UEMS) e, no atual momento, estou cursando o mestrado em Antropologia na Universidade Federal da Grande Dourados (UFGD), com um projeto de pesquisa para construção de uma dissertação de mestrado.

Mas existem também outros jovens dos coletivos Guarani e Kaiowá do meu estado de MS que cursaram e estão cursando diversas faculdades de graduação e pós-graduação, sobretudo, nas Ciências Humanas e na Educação. Conclui a minha graduação na UEMS, unidade do município de Amambai, MS, onde outros jovens kaiowá e guarani estão cursando Ciências Sociais (licenciatura) e História (licenciatura) em grande número, e essa instituição de ensino superior já formou e continua formando números de jovens indígenas desse coletivo na mesma área, Assim é de grande contribuição refletir por esta via sobre as transformações do próprio coletivo e formação das novas gerações Kaiowá e Guarani. 
E, nessa mesma instituição, a produção de monografias e das pesquisas de iniciação científica desenvolvidas pelos indígenas, vem sendo muito importante e diferenciada no âmbito da etnologia indígena. Por meio desses textos informar das ricas produções das pesquisas etnográficas de indígenas que estão sendo realizadas na área de etnologia não só na UEMS, como também em outras várias universidades do Brasil, como na UFGD e Universidade Federal de Mato Grosso do Sul (UFMS), do meu estado de Mato Grosso do Sul.

Sou também acadêmico da Licenciatura Intercultural Indígena- teko arandu da Faculdade Intercultural Indígena - UFGD -, isto é, uma licenciatura diferenciada e específica para os Guarani e kaiowá do Cone Sul de Mato Grosso do Sul, que é o fruto dos movimentos de lideranças Guarani e Kaiowá, que se iniciou desde a década de 1970. Com a vasta experiência na minha graduação, que não é específico e intercultural na UEMS, pude observar, aí na faculdade indígena, o diferenciado em vários aspectos e sentidos. Não estou me referindo aqui sobre qualquer diferenciado, mas sim sobre os aspectos epistemológicos ou saberes que estão sendo produzidos ali pelos próprios Guarani e Kaiowá, ou seja, na construção de rede de relação e de produção de conhecimentos.

Mesmo nessa instituição, a maioria dos docentes não sendo indígenas (mas pesquisador e especialista em torno desses coletivos), as produções de relações e as produções de saberes vêm sendo diferenciado, conforme as características próprias desses coletivos do Cone Sul de Mato Grosso do Sul. Por que, esse curso de licenciatura indígena compõe várias pessoas kaiowá e guarani de diferentes parentelas e de comunidades - tekoha. Esse curso compõe indivíduos multifacetados, pessoas de diferentes aldeias kaiowá e guarani, e a relação e produção de grupo aí são complexas e interessantes.

As pesquisas ou monografias que estão sendo desenvolvidas, ou já foram desenvolvidas, têm sido muito importantes não só na área de etnologia e, do mesmo modo, em outras áreas das Ciências Humanas. A meu ver, pelo motivo de demonstrar as características das etnografias produzidas pelos próprios indígenas sobre a figuração sociológica, cosmológica e sociopolítica do seu coletivo. Vale ressaltar que, nessa licenciatura indígena, as pesquisas vêm sendo produzidas não só na área de Ciências Humanas, mas também nas áreas: de linguagem, Ciências Exatas e nas Ciências de Natureza. Conforme a história dos indígenas em 
academias, essas produções etnográficas dos próprios indígenas são extremamente inovadoras na área de Antropologia/Etnologia e Ciências Humanas em geral.

Os acadêmicos kaiowá e guarani exceto da licenciatura indígena teko arandu, estão em diferentes cursos de ensino superior, como em matemática, biologia, geografia, arte, Ciências Sociais, engenharia, direito, e entre outros. Nesse sentido, os universitários kaiowá e guarani vivenciam dois mundos, que é da universidade e no mundo do seu parentesco e comunidade. Isso pode gerar impacto e que pode construir um kaiowá muito diferente do passado, com dois pensamentos: sobre o seu coletivo e o da universidade.

\section{OS KAIOWÁ E GUARANI DE MS NA PÓS-GRADUAÇÃO STRICTO SENSU}

Nos últimos anos, vem crescendo o número de indígenas na pós-graduação (no mestrado e doutorado); no entanto as dissertações e as teses desses indígenas vêm sendo diferenciado na antropologia e no campo das ciências humanas.

Dentre os autores indígenas, destacamos a discussão proposta pelo antropólogo kaiowá Tonico Benites (2014) em sua tese de doutorado, sobre o movimento indígena e os conhecimentos e práticas colocados em operação na reocupação de seus territórios tradicionais. Como integrante de um coletivo kaiowá específico, a parentela Benites da comunidade de Jaguapiré, mas inserido no movimento indígena, o autor trouxe em sua pesquisa um olhar indígena sobre a questão da resistência e reocupação de territórios de ocupação tradicional de um grande número de famílias e comunidades expropriadas pelas frentes de expansão agropastoris.

O autor indígena demonstra a importância da volta aos territórios tradicionais para a existência dos coletivos kaiowá, apresentando como o retorno ao território acontece simultaneamente à recomposição desses coletivos e como a atualização de práticas e conhecimentos, em especial as rezas, reforçam todo esse processo.

O autor kaiowá pesquisa a reocupação do território tradicional e, ao mesmo tempo, está inserido nos movimentos indígenas.

Gostaria de destacar que para me formar no curso de Antropologia pesquisei os meus povos Guarani e Kaiowá. No momento atual, já como antropólogo, continuo pesquisando as demandas dos povos Guarani e Kaiowá, que possuem uma trajetória específica, uma luta e resistência histórica diante da política 
de dominação e territorialização, promovido pelo Estado brasileiro ao longo do século XX. Para desenvolver uma breve análise sobre algumas funções dos antropólogos indígenas no contexto atual, é preciso mencionar que um indígena formado em Antropologia é antropólogo-pesquisador e ao mesmo tempo é membro permanente de um povo indígena, que pode ser participante da rede de movimento e articulação política regional e nacional dos povos indígenas. No contexto histórico contemporâneo, os indígenas após estudarem, pesquisarem e se formarem em Antropologia não podem se desvincular tanto de seu povo pesquisado quanto de estudos antropológicos e do grupo de pesquisadores da área de Antropologia. Observo que alguns indígenas já formados e estudantes em Antropologia passam a assumir a função de relator e porta voz de seu povo; tradutores das reivindicações e dos projetos dos povos indígenas que são enviados aos órgãos do Estado e às organizações das sociedades nacionais e internacionais. Além disso, um antropólogo indígena já começa a assumir a função de consultor, perito e tradutor do governo e justiça federal. Em diversos espaços dos órgãos públicos, nas ocasiões das reuniões e assembleias intercomunitárias e interétnicas, em geral, os antropólogos e estudantes indígenas foram e são acionados para explicitar e traduzir algumas políticas públicas e programas sociais dos sistemas do Estado brasileiro para os povos indígenas. Dessa forma, o indígena formado em Antropologia começa a conviver e circular nos dois sistemas socioculturais, políticos e conhecimentos complexos e distintos. Assim os antropólogos indígenas passam a traduzir as políticas do governo aos povos indígenas, isto é, esses estudantes indígenas tentam traduzir tanto para os povos indígenas quanto para os agentes do Estado brasileiro. (BENITES, 2015, p. 245-6).

Já Elda Vasques Aquino (2012), pertencente à parentela Vasques, também moradora da Reserva de Amambaí, produziu uma pesquisa sobre a criança indígena kaiowá em sua dissertação de mestrado na área da Educação. A autora discute o processo da aprendizagem própria da criança kaiowá fora do espaço escolar, na situação de convivência em seu próprio coletivo parental. Demonstra como a educação da criança é transformada no processo profundo de mudanças no espaço e nas formas de convivência instituídos na reserva. Convivendo com muitos coletivos distintos, a criança passa a acessar conhecimentos que transcendem aqueles rotineiramente repassados pelos próprios familiares. A dissertação fornece uma série de elementos para pensar a diversidade de modos de produção de coletivos na situação de reserva.

É uma pesquisa etnográfica por apresentar a prática da observação, da descrição das dinâmicas interativas e comunicativas como uma das mais 
relevantes técnicas feitas por mim durante o desenvolvimento deste trabalho. Assim, ao avaliar possíveis soluções para os problemas e impasses identificados, devem-se levar em conta as evidências da observação e das descrições dos elementos cruciais na atividade etnográfica. Observar e descrever o meu próprio jeito de ser e da minha comunidade a qual convivemos diariamente sem perceber as várias transformações que acontecem me levou a ter outro e novo olhar para a pesquisa etnográfica, fui percebendo que as comunidades indígena e principalmente meu povo estão sim se adequando as mudanças sem esquecer suas raízes e seu jeito de ser. Vivi uma experiência diferente que como pesquisadora tinha que ter olhar de academia e ao mesmo tempo sendo eu a própria investigada, que me abriu concepção que tinha que atravessar para outro lado da fronteira, trazendo o Eu sempre, uma inter-relação que não se pode separa, se negocia. Após a análise da pesquisa é necessária uma rever a renegociação dos momentos atuais com os espaços de fronteira para reescrever as intervenções culturais que tem que ser renovadas a cada passo, sem esquecer as raízes do passado. Com esse resultado espero que haja um avanço na valorização de aprendizagem diferenciada com as crianças, para que possa sair do estranhamento que the foi posto. Aqueles que chegam com um jeito diferente na escola, apesar de saberem muitas coisas, são tratados como se não soubessem nada da vida e nem da vivência que já aprenderam, de acordo com sua necessidade na família. (AQUINO, 2012, p. 15-6).

Depois de realizar minha pesquisa junto à comunidade a qual pertenço, digo que concluo em parte meu trabalho. Vejo que ainda preciso continuar a desenvolvê-lo, para poder dizer "conclusão final". Sei que nunca terei uma pesquisa acabada, sempre terei que continuar respondendo várias perguntas como educadora e mulher indígena. Para nós Kaiowá existe o agora, o amanhã pertence a deus. Hoje os indígenas devem lutar para recuperar seus territórios tradicionais, só assim estaremos seguros para continuar nossa sobrevivência. (AQUINO, 2012, p. 105-7).

O pesquisador kaiowá Izaque João (2011) desenvolveu uma dissertação em História sobre o batismo de milho saboró e ritual de jerosy puku - cantos longos, ritual que faz parte da produção de agricultura e dos alimentos tradicionais kaiowá.

O trabalho possibilita também compreender a importância do xamã nessa produção de alimentos, sendo ele que coordena e lidera os rituais e que também fazem comunicação constante com os seres sobrenaturais, como os donos das plantas e comidas. $\mathrm{O}$ autor demonstra que o patrimônio de rezas e objetos rituais se transfere de uma geração a outra e que o local onde são realizados os rituais ficam impregnados pela bendição das rezas, sendo propícias a convivência 
humana harmônica e a recomposição dos coletivos que aí viveram. Os locais onde, no passado, se realizaram esses rituais são agora reivindicados pelos parentes dos que aí viveram no passado. Dessa forma, traz importantes referências para pensar a reprodução dos módulos organizacionais no tempo e no espaço.

Espero que o presente estudo, realizado de dentro da sociedade kaiowá para fora, possa servir, inicialmente, de registro de alguns de nossos cantos kaiowá, os quais certamente servirão para refletirmos sobre o nosso modo de ser (nhande rokoha kaiowa). Espero ainda que sirva para a valorização e o respeito da sociedade Kaiowá perante a sociedade nacional dos karai kuera ou não-índios. E por último, registro que pretendo dar continuidade às pesquisas aqui apresentadas, porém dentro de prazos maiores em relações aos exigidos para a conclusão de uma dissertação de mestrado. (JOÃO, 2011, p. 22).

Estudar a história do meu povo e a história do mborahéi foi extremamente significativo na minha experiência de vida pessoal. Isso porque a realização da festa do jerosy puku, na concepção kaiowá, é uma forma de afirmação da identidade e para a continuidade da existência dos produtos agrícolas por longo tempo. (JOÃO, 2011, p. 116).

Claudemiro Pereira Lescano (2016), pesquisador kaiowá, produziu uma dissertação sobre os pilares de educação kaiowá, e as tentativas de aplicação dessa educação na escola. Analisa o modo de ser tradicional- teko yma guare e o modo de ser atual teko angagua. Nessa oscilação pendular entre os dois modos de ser, se situa a transformação, o que pode ser muito instrutivo para pensar a vida social na reserva.

Essa pesquisa traz uma perspectiva muito grande como instrução e orientação sobre os processos próprios de ensino e aprendizagem do povo Kaiowá fora da escola. Muitos desses elementos culturais precisam, urgentemente, ser incorporados ao modelo pedagógico da escola indígena, não como processos próprios de ensino-aprendizagem desconhecidos, mas como característica dos processos de ensino e aprendizagem escolar e acadêmica. Hoje me apoio no campo de dois conhecimentos: os saberes indígenas e os saberes ditos científicos. Este dois saberes é o único caminho para formar um bom Kaiowá, hoje. A escola tem a liberdade de se reinventar, construir estratégias para a reconstituição o fortalecendo da identidade do povo, enquanto também trabalha no campo social para preparar o cenário por onde a juventude transitará fora da escola. Em consideração aos jovens e à geração atual, o retorno para casa será por meio de leitura e escrita; e a 
escola é ferramenta especial para criar o novo caminho de retorno, em que haverá o fortalecimento da identidade e a compreensão da interculturalidade. (LESCANO, 2016, p. 106-7).

Eliel Benites, da parentela Benites da reserva de Caarapó, em sua dissertação de mestrado, reflete sobre processo de reconstrução e desconstrução da Educação Escolar Indígena em sua reserva. O autor buscou discutir a possibilidade de uma escola indígena para além da escola colonialista e assimilacionista. Embora o foco seja na educação, a discussão gira em torno da possibilidade de construção de iniciativas coletivas na reserva, a partir da criação de Fórum Indígena, de realização anual, envolvendo lideranças, professores, profissionais de saúde e instituições que atuam na reserva.

A prática pedagógica deve contribuir para que o sujeito construa o caminho, utilizando as experiências, os diversos olhares, buscando a integração e a diversidade. $\mathrm{O}$ que buscamos é a retomada a uma posição onde a natureza é uma rede de interligação física, espiritual, social, ambiental, e o papel do homem neste contexto é atuar para fortalecer esta rede a partir da consciência crítica e reflexiva. As particularidades e as possibilidades da vivência do teko marangatu, no contexto da educação escolar indígena, e a busca constante de subversão dos currículos são dimensões que possibilitam o diálogo intercultural entre o sujeito kaiowá e guarani e outras culturas. O processo de subjetivação nesta trajetória da escola indígena é o que possibilita a formação dos "novos sujeitos kaiowá e guarani". (BENITES, E., 2014, p. 128).

Os antropólogos Indígenas se apropriam, de certa forma, procurando, na antropologia ou nos conhecimentos ditos científicos, um olhar mais amplo e estratégia para interpretar o mundo de diversas maneiras. Esses antropólogos indígenas e outros cientistas sociais indígenas vivenciaram, até o atual momento, as injustiças com que o país ou estado se posiciona contra os seus coletivos; refletem sobre essas injustiças e desafios como liderança da sua comunidade. Nesse sentido, os cientistas sociais indígenas buscam, através de pesquisas científicas, a possibilidade de mostrarem um novo olhar sobre o seu mundo e o mundo do outro (que é Ocidental), permeando nesses dois mundos diferentes. Porque não existe somente o único olhar humano no mundo, mas sim pensar o mundo humano em sua pluralidade e olhares, conforme a própria diversidade humana.

O que as ciências sociais e a Antropologia podem nos oferecer, de certa forma, exatamente os conhecimentos que os brancos ocidentais possuem sobre a 
humanidade e mundo. Em minha opinião, esses conhecimentos científicos sobre a humanidade e mundo são profundamente interessantes e importantes para nós indígenas conhecer, porque, em conjunto com essa ciência do branco, é que vamos produzir diálogos e trazer um olhar extremamente inovador não só para a antropologia, como também em outras áreas de ciências humanas e sociais, como pesquisador e cientista intelectuais indígenas.

O que seria legal, em minha opinião como estudante e pesquisador da área de antropologia, são de que, em conjunto, os antropólogos indígenas e antropologia caminhar em busca de uma produção de conhecimentos menos totalitária, do ponto de vista epistêmica. Pela minha leitura sobre os textos de antropólogos indígenas, é exatamente produzir conhecimento de outra forma, distanciando-se do olhar preconceituoso sobre a diversidade humana conforme as epistemologias de diferentes coletivos indígenas.

\section{CONSIDERAÇÕES FINAIS}

A ciência indígena não pode ser caracterizada menos do que a ciência Ocidental, mas sim pensada na interação ou no diálogo entre esses diferentes conhecimentos que existem no mundo. Também, é preciso tirar os conhecimentos indígenas da concepção tradicional, ou seja, descartar da esfera da antiguidade ao qual se percebe como antigo e ultrapassado; num olhar mais profundo desses conhecimentos, percebe-se o valor epistemológico que ele possui. Da mesma forma, as produções científicas de indígenas nas universidades, devemos olhar esses trabalhos como uma outra forma de pensar e fazer antropológico.

Mas, para além (ou antes) de um diálogo entre o pensamento indígena e as ciências, o que mais importa é ater-nos, antes, à diferença e singularidade das teorias indígenas. O que pressupõe pensá-las fora do jogo da oposição ciência versus pensamento tradicional, como bem sugere Boaventura de Sousa Santos (2006, p. 101), para quem tal dissociação permite "pensar os termos das dicotomias fora das articulações e relações de poder que os unem". O esforço etnográfico e as sínteses produzidas até o momento para pensar os povos da Amazônia (e do continente sul-americano como um todo) nos permitem ir adiante. Grosso modo, não só atentando para o que dizem os "intelectuais indígenas" sobre suas teorias, o que já não é pouco, mas, sobretudo, prestar atenção e entender o que eles têm a dizer sobre nossas teorias, antropológicas ou não. Isso nos auxiliará - tomando 
aqui emprestado as palavras de Geertz (1989, p. 24) - a ganhar acesso ao mundo conceitual no qual nossos sujeitos vivem, e, assim, possibilitar- nos, no sentido lato, conversar com eles. (SANTOS; DIAS JR., 2009; p. 156).

Recentemente, com o acesso dos indígenas a conhecimentos ditos científicos e Ocidentais e no ingresso na pós-graduação (mestrado e doutorado), sobretudo, na Antropologia, que desde então passou a se pensar numa possibilidade de uma antropologia indígena, de certa forma explorariam as possibilidades da elaboração de Outras Antropologias, ou antropologias "nativas". Esta, uma discussão estimulada por pesquisadores como o antropólogo francês Bruce Albert e juntamente com o xamã Yanomami Davi Kopenawa (KOPENAWA; ALBERT, 2015), que publicaram um livro que apresenta um diálogo desenvolvido durante décadas entre duas antropologias, a ocidental e a Yanomami. O livro tem gerado grande impacto no modo de pensar as possibilidades da produção antropológica, o que se expressa também em trabalhos como o do indígena Tukano João Paulo Lima Barreto (BARRETO, 2013; BARRETO; MENDES, 2015), dentre outros indígenas que têm participado ativamente desse movimento de renovação do pensar e fazer etnológico, demonstrando que é possível pensar em termos de outras antropologias que não a feita por Ocidentes.

Nesse debate se inserem pesquisadores kaiowá do MS que cursaram pós-graduação stricto sensu, como por exemplo, Tonico Benites (2014), Eliel Benites (2014), Elda Vasques Aquino (2012), Claudemiro Lescano (2016), Isaque João (2011), dentre outros.

A entrada dos Kaiowá e guarani na pós-graduação é recente, e é possível que, muitas vezes, os estudos por eles realizados, em certa medida, a se conformar aos modelos impostos pela academia. Mesmo assim, partimos da hipótese de que será possível identificar diferenças na apresentação do conhecimento indígena, nos textos produzidos por eles próprios. O que devemos procurar é assumir uma atitude consciente em relação à necessidade de buscar formas de apresentação do conhecimento indígena a partir de suas próprias matrizes conceituais, em diálogo com os conceitos da própria antropologia. Nesse sentido, podemos pensar, através das leituras de textos produzidos por indígenas, procurando identificar como o pensamento kaiowá e guarani aí se expressa.

Essa aproximação permitirá identificar em que medida se sustenta a especificidade de uma antropologia indígena, no caso de uma antropologia kaiowá (kaio- 
wálogia) ou uma antropologia guarani (guaranilogia), e como ela pode dialogar com as formulações presentes nos textos produzidos por pesquisadores não indígenas.

\section{REFERÊNCIAS}

AQUINO, Elda Vasques. Educação Escolar Indígena e os processos próprios de aprendizagens: espaços de inter-relação de conhecimentos na infância Guarani/Kaiowá, antes da escola, na comunidade indígena de Amambai, Amambai-MS. 2012. Dissertação (Mestrado em Educação)- Universidade Católica Dom Bosco, Campo Grande, MS, 2012.

BARRETO, João Paulo Lima. WaiMahsã: peixes e humanos um ensaio de antropologia indígena. Dissertação (Mestrado em Antropologia)- Universidade Federal do Amazonas, Manaus, AM, 2013.

BARRETO, João Paulo Lima, MENDES, Gilton. De peixes e homens: por uma outra antropologia. Les Temps Modernes, n. 686, nov./dez. 2015.

BENITES, Eliel. Oguata Pyahu (Uma nova caminhada) no processo de desconstrução e construção da educação escolar indígena da Aldeia Te'ýikue. 2014. 130f. Dissertação (Mestrado em Educação)- Universidade Católica Dom Bosco, Campo Grande, MS, 2014.

BENITES, Tonico. Os antropólogos indígenas: desafios e perspectivas. Novos Debates, Brasília, v. 2, n. 1, janeiro, 2015.

. Rojerokyhina há roikejevytekohape (rezando e lutando): o movimento histórico dos AtyGuasu dos Ava Kaiowa e dos Ava Guarani pela recuperação de seus tekoha. 2014. Tese (Doutorado em Antropologia Social)- Museu Nacional/Universidade Federal do Rio de Janeiro, Rio de Janeiro, RJ, 2014.

JOÃO, Izaque. JakairaRekoNheypyrũMarangatuMborahéi: origem e fundamentos do canto ritual JerosyPuku entre os kaiowá de Panambi, Panambizinho e Sucuri'y, Mato Grosso Do Sul. 2011. Dissertação (Mestrado em História)- Universidade Federal da Grande Dourados, Dourados, MS, 2011.

KOPENAWA, Davi; ALBERT, Bruce. A queda do céu: palavras de um xamã Yanomami. São Paulo: Companhia das Letras, 2015.

LESCANO, Claudemiro Pereira. Tavyterã Reko Rokyta: os pilares da educação guarani kaiowá nos processos próprios de ensino e aprendizagem. 2016. Dissertação (Mestrado em Educação)- Universidade Católica Dom Bosco, Campo Grande, MS, 2016.

SANTOS, Gilton Mendes dos; DIAS JR., Carlos Machado. Ciência da floresta: por uma antropologia no plural, simétrica e cruzada. Revista de Antropologia, São Paulo, v. 52, n. 1, jan. 2009. 


\section{Sobre o autor:}

Celuniel Aquino Valiente: Pertence à etnia Kaiowá, sendo falante nativo da língua Kaiowá. Mestrando no Programa de Pós-Graduação em Antropologia da Faculdade de Ciências Humanas, da Universidade Federal da Grande Dourados (PPGAnt/ FCH/UFGD). Graduado em Ciências Sociais pela Universidade Estadual de Mato Grosso do Sul (UEMS); graduando em Licenciatura Intercultural Teko Arandu nas áreas de Ciências Humanas pela Faind/UFGD. E-mail: celunielvaliente@gmail.com

Recebido em 4 de dezembro de 2017

Aprovado para publicação em 21 de dezembro de 2017 
